\title{
Acknowledgement of "no fault" medical injury: review of patients' hospital records in New Zealand
}

Peter Davis, Roy Lay-Yee, Alastair Scott, Robin Briant, Stephan Schug

Investigations of the epidemiology of adverse events have advanced the safety of patients in hospital. ${ }^{1}$ These studies, however, were done in tort jurisdictions, where the fear of litigation may have inhibited frank and open discussion. $^{2}$ New Zealand abolished tort liability in 1972, instead providing an administrative system of compensation without the need to prove fault. ${ }^{3}$ We analysed data on adverse events in hospitals in New Zealand and the extent to which medical injury is acknowledged in patient records.

\section{Participants, methods, and results}

We took data on patient admissions from a representative sample of 13 from the 20 public hospitals with 100 or more beds. The survey population comprised all patients admitted in 1998 (excluding day patients, psychiatric patients, and patients attending just for rehabilitation). We reviewed the records of sampled patients retrospectively in two stages. To qualify as an adverse event, an incident had to have occurred or been detected by a healthcare professional during the sampled admission. ${ }^{1}$

We defined an adverse event as an unintended injury resulting in disability that was likely to have been caused by healthcare management rather than the underlying disease. We defined an acknowledgement as an annotation in a patient's record indicating or suggesting that healthcare management had caused the medical injury.

Of the 6579 admitted patients who were screened according to set criteria (see bmj.com), the records of 4119 were reviewed by doctors using a structured pro- tocol. Doctors judged 883 patients as having unintended injuries and resulting disabilities, and they assessed whether healthcare management had caused these injuries. Reviewers considered whether any note in the medical records indicated or suggested that healthcare management had caused the injuries.

After adjusting for sample design, reviewers classified 672/717 (94\%) patients with records acknowledging injury as having had an adverse event compared with $81 / 166(47 \%)$ patients whose records did not have such acknowledgement (relative risk 2.01; 95\% confidence interval 1.75 to 2.32 ). We did similar calculations for subsets of adverse events that occurred in hospital (table). We estimated relative risks using the Mantel-Haenszel method and adjusted for the sample design (stratified cluster). Relative risks were greater for higher impact incidents and for "non-preventable" events.

For almost $672 / 753(90 \%)$ adverse events, an annotation in the patient's record acknowledged medical injury. More than 148/181 (80\%) adverse events involving systems failure in hospital were annotated.

\section{Comment}

Annotations in patients' records were a good predictor that a medical injury had been caused by healthcare management, regardless of clinical context. Fear of litigation may be an obstacle to reporting errorparticularly for high impact, preventable, and systemic events. Our results show that the level of acknowledgement of medical injury in patients' records can be
Department of Public Health and General Practice, Christchurch School of Medicine and Health

Sciences, University of Otago, PO Box

4345, Christchurch, New Zealand

Peter Davis professor

Division of Community Health Faculty of Medical and Health

Sciences, University of Auckland, Auckland, New Zealand

Roy Lay-Yee analyst

Robin Briant clinical director

Department of Statistics, University of Auckland

Alastair Scott professor

Department of Anaesthesia, University of Western Australia, Perth, Australia Stephan Schug professor

Correspondence to: P Davis

peter.davis@ chmeds.ac.nz

Acknowledgement of medical injury in patients' hospital records in New Zealand $\left(n=883^{\star}\right)$

\begin{tabular}{|c|c|c|c|c|c|}
\hline \multirow[b]{2}{*}{ Adverse events in hospital } & \multicolumn{2}{|c|}{ Injury annotated $(\mathrm{n}=717)$} & \multicolumn{2}{|c|}{ No injury annotated $(n=166)$} & \multirow[b]{2}{*}{ Relative risk $(95 \% \mathrm{CI}$} \\
\hline & No & $\% \dagger$ & No & $\% \dagger$ & \\
\hline All $(n=604)$ & $536 / 581$ & 92 & $68 / 153$ & 42 & $2.19(1.84$ to 2.60$)$ \\
\hline \multicolumn{6}{|l|}{ Hospital type: } \\
\hline Tertiary $(n=296)$ & $268 / 298$ & 90 & $28 / 76$ & 35 & 2.54 (1.87 to 3.43$)$ \\
\hline Secondary $(n=308)$ & $268 / 283$ & 95 & $40 / 77$ & 49 & 1.92 (1.57 to 2.35$)$ \\
\hline \multicolumn{6}{|l|}{ Clinical riskł: } \\
\hline High $(n=400)$ & $353 / 379$ & 93 & $47 / 91$ & 50 & 1.89 (1.47 to 2.42$)$ \\
\hline Low $(\mathrm{n}=204)$ & $183 / 202$ & 90 & $21 / 62$ & 32 & 2.80 (1.85 to 4.23$)$ \\
\hline \multicolumn{6}{|l|}{ Patient impact§ी: } \\
\hline Permanent disability or death $(\mathrm{n}=83)$ & $73 / 118$ & 62 & $10 / 95$ & 9 & 6.64 (3.97 to 11.07$)$ \\
\hline Temporary disability lasting $<1$ year $(\mathrm{n}=499)$ & $446 / 491$ & 91 & $53 / 138$ & 37 & 2.48 (2.03 to 3.02$)$ \\
\hline \multicolumn{6}{|l|}{ Preventability§: } \\
\hline Evidence $(\mathrm{n}=366)$ & $313 / 358$ & 87 & $53 / 138$ & 36 & 2.44 (1.94 to 3.05$)$ \\
\hline No evidence $(\mathrm{n}=238)$ & $223 / 268$ & 83 & $15 / 100$ & 15 & 5.69 (3.32 to 9.77$)$ \\
\hline \multicolumn{6}{|l|}{ Systems failure§: } \\
\hline Evidence of $(n=181)$ & $148 / 193$ & 76 & $33 / 118$ & 26 & $2.93(2.12$ to 4.03$)$ \\
\hline No evidence of $(n=423)$ & $388 / 433$ & 89 & $35 / 120$ & 27 & 3.28 (2.56 to 4.20$)$ \\
\hline
\end{tabular}

*Includes 753 cases judged to be adverse events, of which 604 occurred in hospital.

†Adjusted for sample design.

¥Major diagnostic categories (based on the Australian Diagnostic Related Group classification system 3.1) were classified into two groups according to the percentage of admissions associated with an adverse event in hospital $(>9.2 \%$ and $\leqslant 9.2 \%$ where $9.2 \%$ was the mean).

$\S$ Adverse events were compared to the 130 non-adverse events, except for the hospital type and clinical risk subsets, in which admissions from the same group were used.

शExtent of disability could not be determined from the medical records of 22 patients. 
remarkably high in a no fault jurisdiction and strongly predictive of such occurences.

Doctors in many countries are discouraged from reporting medical errors, ${ }^{4}$ yet litigation in tort jurisdictions is becoming more common. ${ }^{5}$ In no fault jurisictions, the relatively high level of annotation in patient records that we found could provide a basis for more vigorous error reporting.

Contributors: PD designed the study and wrote the paper. RL-Y undertook the analysis, advised by AS. RB organised and oversaw the clinical assessments. SS provided technical advice. PD is guarantor.

Funding: Health Research Council of New Zealand.
Competing interests: None declared.

1 Davis P, Lay-Yee R, Briant R, Schug S, Scott A, Johnson S, et al. Adverse events in New Zealand public hospitals: principal findings from a national survey. Wellington: Ministry of Health, 2001. (Occasional paper No 3.) www.moh.govt.nz/moh.nsf (accessed 25 Nov 2002).

2 Gostin L. A public health approach to reducing error: medical malpractice as a barrier. JAMA 2000;283:1742.

3 Miller RS. An analysis and critique of the 1992 changes to New Zealand's accident compensation scheme. Maryland Law Rev 1993;52:1070-92.

4 Blendon RJ, Schoen C, Donelan K, Osborn R, DesRoches CM, Scoles K, et al. Physicians' views on quality of care: a five-country comparison. Health Aff 2001;20:233-43.

5 National Audit Office. Handling clinical negligence claims in England. London: Stationery Office, 2001

(Accepted 26 July 2002)

\section{Review of deaths related to taking ecstasy, England and Wales, 1997-2000}

Fabrizio Schifano, Adenekan Oyefeso, Lucy Webb, Mike Pollard, John Corkery, A Hamid Ghodse

National

Programme on

Substance Abuse

Deaths, Department

of Addictive

Behaviour and

Psychological

Medicine, St

George's Hospital

Medical School,

London SW17 0RE

Fabrizio Schifano

senior lecturer

Adenekan Oyefeso

senior lecturer

Lucy Webb

research nurse

Mike Pollard

database officer

John Corkery

homorary senio

research fellow

A Hamid Ghodse

chairman

Correspondence to:

F Schifano

f.schifano@

sghms.ac.uk

BMJ 2003;326:80-1
The lack of data about the lethal consequences of taking ecstasy has led to high profile reports of deaths in the media and also the idea that ecstasy is safe. The United Kingdom accounts for most of the ecstasy tabletsnormally containing methylenedioxymethamphetamine (MDMA) or 3,4-methylenedioxyamphetamine (MDA)-seized in the European Union. ${ }^{1}$ The rate of deaths related to taking ecstasy in people aged 15-24 during 1995 and 1996 in England was 18 and between 1995 and 1997 in Scotland was 11. ${ }^{2}$ The risk of using ecstasy varies between one death in 2000 first time users to one death in 50000 first time users. ${ }^{2}$

The National Programme on Substance Abuse Deaths was established after the Home Office Addicts Index closed. We report all the information recorded in the programme's database between 1 July 1997 and 30 June 2000 about deaths in England and Wales related to taking ecstasy.

\section{Participants, methods, and results}

Deaths are included on the database of the National Programme on Substance Abuse Deaths if one or more psychoactive substances are directly implicated in death, if the patient had a history of dependence on or misuse of psychoactive drugs, or if controlled drugs are found during necropsy. The response rate from coroners in England and Wales was high (about 95\%). ${ }^{3}$ We defined deaths related to ecstasy as a coroner's report including the text "ecstasy," "XTC," "MDMA," or "MDA."'

We identified 81 deaths related to taking ecstasy. Results of toxicological examination were made available in 75 cases; MDMA accounted for 68 (91\%), MDA for 7 (9\%), and opiates or opioids for $44(59 \%)$ of these cases. In $26(38 \%)$ cases, one or more drugs (mostly hypnotics or sedatives) had been prescribed to the deceased patient (table).

\section{Comment}

Most people who died from taking ecstasy were white employed men in their late 20 s, known to services as
Characteristics of 81 people whose death was related to ecstasy in England and Wales between 1 July 1997 and 30 June 2000. Values are numbers (percentages) unless stated otherwise

\begin{tabular}{|c|c|}
\hline Characteristic & Value \\
\hline \multicolumn{2}{|l|}{ Sex: } \\
\hline Male & $66(81)$ \\
\hline Female & $15(19)$ \\
\hline Age (years) & 27.2 (range 16-50) \\
\hline \multicolumn{2}{|l|}{ Ethnic origin: } \\
\hline White & $71(88)$ \\
\hline Black African & $3(4)$ \\
\hline Other & $7(9)$ \\
\hline \multicolumn{2}{|l|}{ Employment status: } \\
\hline Employed & $37(46)$ \\
\hline Unemployed & $36(44)$ \\
\hline Student & $8(10)$ \\
\hline Patients known as drug addicts to services or primary care & $46(57)$ \\
\hline \multicolumn{2}{|l|}{ Most common causes of death recorded by coroners: } \\
\hline Polysubstance poisoning & $50(62)$ \\
\hline Only MDMA poisoning & $6(7)$ \\
\hline Others" & $25(31)$ \\
\hline \multicolumn{2}{|l|}{ Place of death: } \\
\hline Private residence & $40(49)$ \\
\hline Hospital & $25(31)$ \\
\hline Pub or club & $2(2)$ \\
\hline Other & $14(17)$ \\
\hline \multicolumn{2}{|l|}{ Area of death: } \\
\hline London & $16(20)$ \\
\hline Southeast England & $10(12)$ \\
\hline Northeast England & $11(14)$ \\
\hline Northwest England & $14(17)$ \\
\hline Central England & $11(14)$ \\
\hline Other & $19(23)$ \\
\hline \multicolumn{2}{|l|}{ Month of death: } \\
\hline January & $10(12)$ \\
\hline July & $10(12)$ \\
\hline August & $8(10)$ \\
\hline $\begin{array}{c}\text { Other } \\
\end{array}$ & $53(65)$ \\
\hline \multicolumn{2}{|l|}{ Day of death: } \\
\hline Saturday & $16(20)$ \\
\hline Sunday & $29(36)$ \\
\hline Other & $36(44)$ \\
\hline
\end{tabular}

${ }^{\star}$ For example heart attack, trauma, drowning, or hyperpyrexia. 